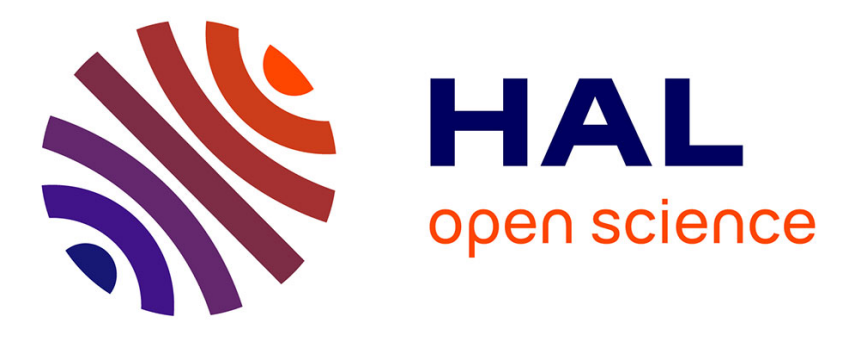

\title{
Whole limb push-off work in people with transtibial amputation during slope ascent
}

Coralie Villa, Boris Dauriac, Joseph Bascou, Xavier Bonnet, Pascale Fodé, Hélène Pillet

\section{- To cite this version:}

Coralie Villa, Boris Dauriac, Joseph Bascou, Xavier Bonnet, Pascale Fodé, et al.. Whole limb push-off work in people with transtibial amputation during slope ascent. Computer Methods in Biomechanics and Biomedical Engineering, 2015, 18, pp.2078-2079. 10.1080/10255842.2015.1069631 . hal02565401

\section{HAL Id: hal-02565401 \\ https://hal.science/hal-02565401}

Submitted on 6 May 2020

HAL is a multi-disciplinary open access archive for the deposit and dissemination of scientific research documents, whether they are published or not. The documents may come from teaching and research institutions in France or abroad, or from public or private research centers.
L'archive ouverte pluridisciplinaire HAL, est destinée au dépôt et à la diffusion de documents scientifiques de niveau recherche, publiés ou non, émanant des établissements d'enseignement et de recherche français ou étrangers, des laboratoires publics ou privés. 


\title{
Whole limb push-off work in people with transtibial amputation during slope ascent
}

\author{
C. Villa ${ }^{a, b}$, B. Dauriac ${ }^{b, c}$, J. Bascou ${ }^{a, b}$, X. Bonnet ${ }^{c}$, P. Fodéa and H. Pillet ${ }^{b}$

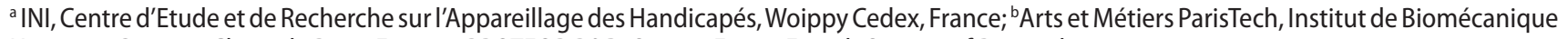 \\ Humaine Georges Charpak, Paris, France; 'PROTEOR R\&D, Seurre, FranceFrench Society of Biomechanics
}

KEYWORDS Energetic of gait; below-knee amputation; prosthetic foot; uphill walking

\section{Introduction}

Unilateral transtibial amputation impairs locomotion, especially in daily living outdoor situations. As an example, slope ascent requires specific gait adjustments such as hip power generation during single support followed by ankle power generation during second double support. Hip extensor strengthening could help people with transtibial amputation for hip propulsion in slope ascent (Langlois et al. 2014). Energy storage and return (ESAR) foot-ankle prostheses have been designed to absorb and release elastic energy in an attempt to restore some functions of the amputated limb. However, it remains unclear how ESAR feet contribute to center of mass propulsion, especially during slope ascent. Simple models were recently developed to globally analyze gait in an energetic point of view by computing the center of mass mechanical work (Donelan et al. 2002; Kuo et al. 2005). Particularly, several hypotheses permit to estimate for each lower limb the whole limb push-off work during double support (Kuo et al. 2005). Using this approach, step-to-step transition was investigated during level walking, in ablebodied subjects wearing prosthetic foot (Caputo \& Collins 2014) and in people with transtibial and transfemoral amputation (Houdijk et al. 2009; Bonnet et al. 2014), and in slopes in able-bodied subjects (Franz et al. 2012). Up to now, no study quantified prosthetic and contralateral push-off work during slope ascent in a below-knee amputee population. Thus, the aim of the study is to investigate center of mass mechanical work adjustments during the propulsion period during slope ascent for two inclinations of slopes compared to level walking in people with transtibial amputation.

\section{Methods}

Local ethics committee approved the protocol and all participants signed a written form to give their consent. Ten male subjects with transtibial amputation were recruited in the study (age (years) : 51 SD 11 range [33-65], height $(\mathrm{cm}): 176$ SD 5 range [168-182], weight (kg): 86 SD 13 range [66-104], and amputation time (years) : 9 SD 8 range [1-23]). All subjects were fitted with their own prosthesis and all prosthetic feet were ESAR feet. Thirteen non-amputee subjects ( 11 male and two females) were also recruited as a reference (age (years): 39 SD 16 range [19-67], height (cm): 175 SD 8 range [166-192], and weight $(\mathrm{kg})$ : 69 SD 9 range [57-85]).

After a static acquisition, participants were asked to walk, at self-selected speed, in an optoelectronic motion capture laboratory (Vicon V8i, $100 \mathrm{~Hz}$ ), on a flat pathway, on a 5\%-inclined slope (gentle slope) and a 12\%-inclined slope (steep slope). All situations were instrumented with two force platforms (AMTI, $100 \mathrm{~Hz}$ ). Gait speed was averaged on three to five gait cycles in each situation. From the positions of 54 markers, anatomical frames were created and kinematics of the whole body were obtained as described in (Pillet et al. 2014). A personalized volumetric model of the body was created to compute, in each local body segment reference frame, the position of the center of gravity (Pillet et al. 2014). Combined with the anatomical frames kinematics, position and velocity (by derivation) of the body center of mass were obtained in the global reference frame. Then, mechanical power of each individual limb was assessed by the dot product of the velocity of the body center of mass velocity and the ground reaction forces on the lower limb. The whole limb push-off work was evaluated using the curve of the mechanical power along the gait cycle by integration of the positive power during push-off as described by (Kuo et al. 2005).

\section{Results and discussion}

Amputee subjects walked at similar self-selected speed than controls in all situations, revealing a high functional activity in the recruited amputee population (Table 1). Mechanical power curves patterns and lower limb push-off work values are in accordance with previous studies on flat surface for amputees (Houdijk et al. 2009) and on slopes for able-bodied subjects (Franz et al. 2012), giving heed to differences in computation method and walking velocity in these studies. Pushoff mechanical work at the contralateral limb was similar or higher (steep slope ascent) than lower limb push-off work in

CONTACT C.Villa coralie.villa@invalides.fr 
Table 1. Gait speed and lower limb push-off work for nonamputee (NA) and transtibial amputees (TT).

\begin{tabular}{llccc}
\hline & Mean (SD) & $\begin{array}{c}\text { Level } \\
\text { walking }\end{array}$ & $\begin{array}{c}\text { Gentle } \\
\text { slope } \\
\text { ascent }\end{array}$ & $\begin{array}{c}\text { Steep slope } \\
\text { ascent }\end{array}$ \\
\hline NA & Gain-max] speed $(\mathrm{m} / \mathrm{s})$ & $1.38(0.11)$ & $1.26(0.17)$ & $1.26(0.17)$ \\
& & {$[1.22-1.56]$} & {$[0.85-1.56]$} & {$[0.86-1.51]$} \\
& Whole lower limb & $0.27(0.06)$ & $0.38(0.08)$ & $0.46(0.10)$ \\
& push-off work $(\mathrm{J} / \mathrm{kg})$ & {$[0.20-0.42]$} & {$[0.24-0.50]$} & {$[0.32-0.64]$} \\
TT & Gait speed (m/s) & $1.27(0.17)$ & $1.18(0.19)$ & $1.12(0.22)$ \\
& & {$[0.93-1.48]$} & {$[0.82-1.53]$} & {$[0.73-1.48]$} \\
& Prosthetic side & $0.15(0.03)$ & $0.17(0.05)$ & $0.21(0.06)$ \\
& push-off work $(\mathrm{J} / \mathrm{kg})$ & {$[0.11-0.21]$} & {$[0.08-0.23]$} & {$[0.14-0.33]$} \\
& Contralateral side & $0.27(0.08)$ & $0.40(0.12)$ & $0.54(0.15)$ \\
& push-off work $(\mathrm{J} / \mathrm{kg})$ & {$[0.11-0.37]$} & {$[0.14-0.55]$} & {$[0.23-0.72]$} \\
& Prosthetic side & {$[0.93-1.48]$} & {$[0.82-1.53]$} & {$[0.73-1.48]$} \\
& push-off work $(\mathrm{J} / \mathrm{kg})$ & $0.15(0.03)$ & $0.17(0.05)$ & $0.21(0.06)$ \\
& Contralateral side & {$[0.11-0.21]$} & {$[0.08-0.23]$} & {$[0.14-0.33]$} \\
& push-off work $(\mathrm{J} / \mathrm{kg})$ & $0.27(0.08)$ & $0.40(0.12)$ & $0.54(0.15)$ \\
\hline
\end{tabular}

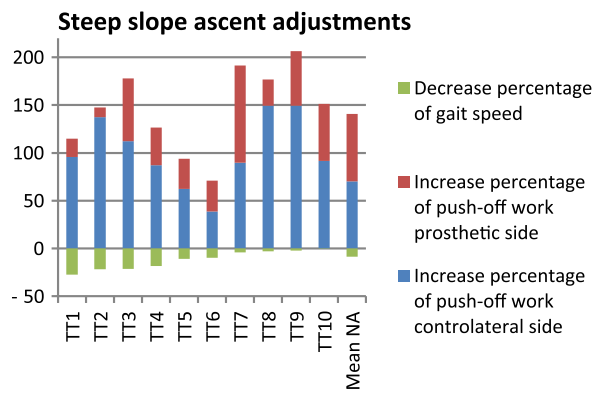

Figure 1. Percentage of gait speed and push-off work adjustment during steep slope ascent compared to level walking for each transtibial amputee (TT) and the average non-amputee population (NA).

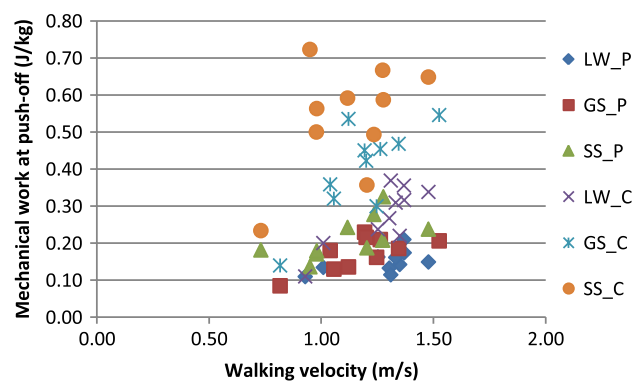

Figure 2. Push-off mechanical work in the prosthetic $(\mathrm{P})$ and contralateral limb (C) for transtibial amputees during level walking (LW), gentle slope ascent (GS), and steep slope ascent (SS) against gait speed.

non-amputees (Table 1). Prosthetic push-off work was twice lower than contralateral one in all situations (Table 1 and Figure 2). All mechanical works increased with ground inclination. However, although prosthetic push-off work increased during steep slope ascent compared to level walking, this percentage of increase remained inferior to non-amputee and contralateral limb rates. Indeed most of patients mainly decreased gait speed and increased contralateral limb push-off work (Figures 1 and 2). In percentage, these adjustments were largely greater than for non-amputees (Figure 1). In addition, contralateral limb work increased more with gait speed than prosthetic limb work (Figure 2). Figure 2 also suggests that to keep decent velocity when ground inclination heightened, patients increased contralateral work at push-off. At the contrary, relationship between prosthetic work and gait speed remained almost the same whatever the slope.

\section{Conclusions}

This study analyzed whole lower limb push-off work of prosthetic limb compared to contralateral limb and controls. Particularly, asymmetrical adjustments were highlighted during slope ascent in transtibial amputees: prosthetic limb only slightly contributed to the production of propulsion during gait and for raising the center of mass during slope ascent. Perspectives of this work include analyses of the link between prosthetic ankle power generation and prosthetic limb push-off work during propulsion in slopes and stairs. Further studies must also analyze lower limb work and hip work in single support during slope ascent. This could provide data to help adjusting timing of prosthetic foot energy restitution in prosthetic design.

\section{Funding}

This study was supported by the French National Research Agency, under reference ANR-2010-TECS-020.

\section{References}

Bonnet X, Villa C, Fode P, Lavaste F, Pillet H. 2014. Mechanical work performed by individual limbs of transfemoral amputees during step-to-step transitions: effect of walking velocity. Proc Inst Mech Eng H. 228:60-66.

Caputo JM, Collins SH. 2014. Prosthetic ankle push-off work reduces metabolic rate but not collision work in non-amputee walking. Sci Rep. 4:7213.

Donelan JM, Kram R, Kuo AD. 2002. Simultaneous positive and negative external mechanical work in human walking. J Biomech. 35:117-124.

Franz JR, Lyddon NE, Kram R. 2012. Mechanical work performed by the individual legs during uphill and downhill walking. J Biomech. 45:257-262.

Houdijk H, Pollmann E, Groenewold M, Wiggerts $H$, Polomski W. 2009. The energy cost for the step-to-step transition in amputee walking. Gait Posture. 30:35-40.

Kuo AD, Donelan JM, Ruina A. 2005. Energetic consequences of walking like an inverted pendulum: step-to-step transitions. Exercise Sport Sci. 33:88-97.

Langlois K, Villa C, Bonnet X, Lavaste F, Fode P, Martinet N, Pillet H. 2014. Influence of transtibial amputee physical capacities on gait adjustments on sloped surface. J Rehabil Res Dev. 51:193-200.

Pillet H, Drevelle X, Bonnet X, Villa C, Martinet N, Sauret C, Bascou J, Loiret I, Dijan F, Rapin N, et al. 2014. APSIC: training and fitting amputees during situations of daily living. IRBM. 35:60-65. 